\title{
GUIDELINES
}

\section{The CanPain SCI Clinical Practice Guidelines for Rehabilitation Management of Neuropathic Pain after Spinal Cord: introduction, methodology and recommendation overview}

\author{
E Loh ${ }^{1,2,3,4}$, SD Guy ${ }^{1,3,4}$, S Mehta ${ }^{1,3,4}$, DE Moulin²,3, TN Bryce ${ }^{5}$, JW Middleton ${ }^{6}$, PJ Siddall ${ }^{6}$, SL Hitzig ${ }^{7}$, \\ E Widerström-Noga ${ }^{8}$, NB Finnerup ${ }^{9}$, A Kras-Dupuis ${ }^{4}$, A Casalino ${ }^{4}$, BC Craven ${ }^{7}$, B Lau ${ }^{10}$, I Côté ${ }^{11}$, D Harvey ${ }^{12}$, \\ C O'Connell ${ }^{13}$, S Orenczuk ${ }^{4}$, AG Parrent ${ }^{3,14}$, P Potter ${ }^{3,4}$, C Short ${ }^{15}$, R Teasell ${ }^{1,3}$, A Townson ${ }^{10}$, C Truchon ${ }^{16}$, \\ CL Bradbury ${ }^{7}$ and D Wolfe $e^{1,3}$
}

Study design: Clinical practice guidelines.

Objectives: The objective was to develop the first Canadian clinical practice guidelines for the management of neuropathic pain in people with spinal cord injury (SCl).

Setting: The guidelines are relevant for inpatient and outpatient SCl rehabilitation settings in Canada.

Methods: The guidelines were developed in accordance with the Appraisal of Guidelines for Research and Evaluation II tool. A Steering Committee and Working Group reviewed the relevant evidence on neuropathic pain management (encompassing screening and diagnosis, treatment and models of care) after SCl. The quality of evidence was scored using Grading of Recommendations Assessment, Development and Evaluation (GRADE). A consensus process was followed to achieve agreement on recommendations and clinical considerations.

Results: The Working Group developed 12 recommendations for screening and diagnosis, 12 recommendations for treatment and 5 recommendations for models of care. Important clinical considerations accompany each recommendation.

Conclusions: The Working Group recommendations for the management of neuropathic pain after SCl should be used to inform practice.

Spinal Cord (2016) 54, S1-S6; doi:10.1038/sc.2016.88

\section{INTRODUCTION}

Pain following spinal cord injury (SCI) is common and often chronic, with $48-92 \%$ of patients experiencing pain. ${ }^{1-7}$ Pain negatively interferes with sleep, return to work, health-related quality of life and participation in social activities. ${ }^{3}$ In addition, pain is associated with poorer rehabilitation outcomes and directly contributes to disability. ${ }^{8}$ Pain after SCI represents a significant challenge for patients living with SCI. ${ }^{9,10}$

The International Association for the Study of Pain defines neuropathic pain (NP) as 'pain caused by a lesion or disease of the somatosensory nervous system'. ${ }^{1} \mathrm{NP}$ is common, with the prevalence of below-level pain after SCI reported as 34\% and at-level pain reported as $42 \% .{ }^{2}$ Specifically within Canada, NP after SCI is the most common complication reported by 1549 people with SCI. ${ }^{3}$

Despite the high frequency of pain in those with SCI and its significant impact on quality of life, management of pain remains challenging. In a survey of 575 people with SCI in the Netherlands, $63.8 \%$ of respondents reported high pain levels (mean 52.8 on a $0-100$ scale) despite various forms of treatment. ${ }^{11}$ In an Australian study of clinicians from a range of disciplines, $65.1 \%$ reported below-level NP and $36.8 \%$ reported at-level pain as the most distressing symptom for their clients..$^{12}$ Of these clinicians, $81.13 \%$ of 242 respondents advised that they felt inadequately resourced to manage patients with post-SCI pain in the community, citing a lack of training, knowledge and specialist access.

Despite the difficulty clinicians have in managing pain after SCI, guidance for clinicians regarding the management of SCI-related NP in the form of clear recommendations within a Canadian context is limited. The lack of such practical guidelines for the management of SCI-related NP may partially explain the findings of a recent environmental scan of SCI rehabilitation at 12 sites in Canada. The scan evaluated several topics including the frequency of use of any type of evidence-based standard of care or treatment guideline in selecting therapy for NP management. ${ }^{13}$ The scan found that only three sites followed a standard of care or used any treatment guidelines. The explanation for this finding is unknown, but it underscores the need for a practical, easy-to-use, evidence-based treatment guideline to support clinical decision-making in the Canadian setting.

\footnotetext{
${ }^{1}$ Lawson Health Research Institute, London, Ontario, Canada; ${ }^{2}$ St. Joseph's Health Care Pain Clinic, London, Ontario, Canada; ${ }^{3}$ Western University, London, Ontario, Canada; ${ }^{4}$ Parkwood Institute, London, Ontario, Canada; ${ }^{5}$ Mount Sinai Hospital, New York, NY, USA; ${ }^{6}$ The University of Sydney, Sydney, New South Wales, Australia; ${ }^{7}$ Toronto Rehabilitation Institute, Toronto, Ontario, Canada; ${ }^{8}$ University of Miami, Coral Cables, FL, USA; ${ }^{9}$ Aarhus University, Aarhus, Denmark; ${ }^{10}$ University of British Columbia, Vancouver, British Columbia, Canada; ${ }^{11}$ Center interdisciplinaire de reserche en réadaptation et integration sociale, Quebec City, Quebec; ${ }^{12}$ Spinal Cord Injury Ontario, Ontario, Canada; ${ }^{13}$ Stan Cassidy Centre for Rehabilitation, Fredericton, New Brunswick, Canada; ${ }^{14}$ London Health Sciences Center, London, Ontario, Canada; ${ }^{15}$ Dalhousie University, Halifax, Nova Scotia, Canada and ${ }^{16}$ Institut National d'Excellence en Santé et Services Sociaux, Montreal, Quebec

Correspondence: Dr E Loh, Department of Physical Medicine and Rehabilitation, Parkwood Institute, Main Building, 550 Wellington Road, London, Ontario, Canada N6C 0A7. E-mail: eldon.loh@sjhc.Iondon.on.ca
} 
The purpose of this project was to (1) create practical, actionable clinical practice guidelines (CPGs) with a strong rating on the Appraisal of Guidelines Research and Evaluation (AGREE) II scale, (2) to support the standardization of care in the management of NP and (3) to identify deficiencies for future research in the area. As a result, a group of international experts, named the CanPainSCI Working Group (WG), was convened to develop, under the direction of the Steering Committee (SC), evidence-based or evidence-informed guidelines for the management of SCI-related NP. Guidelines were to be developed for screening and diagnosis, treatment and models of care, with a focus on the Canadian rehabilitation environment. The target audience for these guidelines is primarily clinicians caring for patients with SCI within the rehabilitation setting and other clinicians involved in the care of SCI patients. Researchers in pain and SCI and health policy experts in SCI may find them useful. The CPG applies to adults with SCI in Canada.

\section{MATERIALS AND METHODS}

\section{Preparatory phase}

The SC (EL, SDG and SM) navigated the overall guideline development process with the assistance of a methodologist informed in CPG development and the WG, which reviewed and provided input at each stage. To prepare for developing the guideline process, the SC participated in a full-day workshop offered by experts in CPG methodology at the Centre for Effective Practice (Toronto, ON, Canada, www.effectivepractice.org). The training workshop, which was led by a clinical expert, an epidemiologist and an information specialist, addressed the following topics: (1) collaborating with content experts to develop a WG and a review board; (2) conducting effective systematic reviews; (3) extracting, evaluating and appraising studies using the Grading of Recommendations Assessment, Development and Evaluation (GRADE) tool; (4) appraising existing CPGs using the AGREE tool; (5) developing actionable recommendations; and (6) facilitating consensus development by the WG. After completing guideline development training, the SC developed the draft CPG process, which was then submitted to the methodologists for review before formation of the WG. The SC consulted the methodologists as needed during the CPG development process.

\section{Literature review}

A previous unpublished review of the literature conducted by the SC identified the gaps and the evidence for this project. On the basis of the scoping review, the SC drafted a series of questions for each topic to be addressed in the guidelines: screening and diagnosis, treatment and models of care for SCI-related NP. A literature search was then performed to address these questions (Supplementary File 1).

Current guidance in the area consists of a pain management algorithm, ${ }^{14}$ a systematic review ${ }^{15}$ and two CPGs. Noting the existence of these CPGs, we evaluated their quality. The Multidisciplinary Association of Spinal Cord Injury Professionals (MASCIP) guidelines were evaluated using the AGREE II tool. ${ }^{16}$ Both the SC and the WG felt that the low rating of the MASCIP guidelines using the AGREE II tool precluded their use as a basis for the current guidelines. ${ }^{17}$ Another CPG was developed by the Association Francophone Internationale des Groupes d'Animation de la Paraplégie, the Société Française de Médecine Physique et de Réadaptation, the Société Française d'Evaluation et de Traitement de la Douleur and the Société Française de Neurochirurgie and released in France. ${ }^{18}$ As substantial differences exist between the Canadian and French medical systems, the French guideline may not apply to the Canadian situation. In addition, the French guidelines achieved a low score using the AGREE II tool, due to unclear presentation of recommendations, lack of specification of target audience, and unclear methodology for recommendation development and writing, including details of the consensus process after evaluation of the scientific evidence and stakeholder views. For this reason, the SC and the WG voted not to consider these guidelines in the development of the CanPainSCI guidelines. Siddall and Middleton ${ }^{14}$ published the only other care pathway for the management of pain in SCI based on available evidence. Although this algorithm is useful in synthesizing the evidence for pain management in SCI, the algorithm did not use a CPG development methodology.

\section{Guideline development process}

The WG was convened to develop the guidelines. The SC recruited members based on the proposed content of the CPG. Experts were identified through literature searches of the three guideline topic areas and through stakeholder and already recruited members' recommendations. The WG included representation from several disciplines nationally and internationally, including physiatry, pain medicine, psychology, allied health and nursing, research, and neurosurgery. In addition, representation was sought from a prominent consumer service provider group, and the peer coordinator from SCI Ontario (DH) agreed to participate. This ensured that the voices of people with SCI were part of the development process. The WG was subdivided into a Screening and Diagnosis WG, a Treatment WG and a Model of Care WG based on expertize, areas of interest, bodies of work and location.

The guideline development process was conducted through a series of 1-h Cisco WebEx (Cisco, Toronto, ON, Canada) meetings facilitated by the SC. The SC also used regular email communications to address outstanding issues and provide material to be reviewed at the following meetings.

At the initial meeting, the CanPainSCI WG finalized the composition of the individual WGs (Table 1). The WG then developed the questions of interest and voted on them to reach a consensus. Questions that reached consensus remained the same, whereas questions on which no consensus could be reached were modified until consensus was reached. The SC synthesized and evaluated the literature to address each question for the subsequent subgroup meetings.

During the initial meeting, the proposed format of the evidence tables and assessment tool was also discussed. The SC and the WG discussed and reached consensus on the criteria and standards for grading evidence for the project.

The quality of the evidence to answer each question was assessed using a modified GRADE process. ${ }^{19}$ The group agreed that the GRADE process would be modified by having the SC, rather than the WGs, assess the evidence. The WG also acknowledged that, because of the generally smaller sample size in the SCI literature, the reviewers should not modify the quality of evidence for studies with a small sample size. After the meeting, two independent SC reviewers evaluated the evidence, assigned a quality of evidence for each study and formulated detailed data tables to address each of the developed questions. Criteria such as study design, potential bias and the presence or absence of significant study limitations determined the quality of evidence (high, moderate, low and very low). In case of disagreement, a third reviewer, blinded to the ratings of the other two reviewers, evaluated the evidence. The SC then provided the WGs with the summary evidence tables at subsequent small subgroup meetings. The WGs reviewed the evidence tables relevant to their area. Each WG developed recommendations for their topic area and assigned a strength of recommendation (strong or weak) in accordance with the GRADE process and with reference to the AGREE II tool. The strength of a recommendation was based on numerous factors 
Table 1 CanPainSCI working group

\begin{tabular}{|c|c|c|c|}
\hline Member & Affiliation & Professional role & Subgroup \\
\hline Cheryl L. Bradbury PhD, CPsych & Toronto Rehabilitation Institute & Psychologist & Treatment \\
\hline Thomas N. Bryce MD & Mount Sinai Hospital & Professor, Physiatrist & $\begin{array}{l}\text { Screening and } \\
\text { Diagnosis }\end{array}$ \\
\hline Alba Casalino BScPT & Parkwood Institute & Physiotherapist & Treatment \\
\hline Isabelle Côté MD, FRCP(C) & Institut Universitaire de Réadaptation & Physiatrist & Treatment \\
\hline $\begin{array}{l}\text { B. Cathy Craven BA, MD, FRCP(C), } \\
\text { MSc, CCD }\end{array}$ & Toronto Rehabilitation Institute & Physiatrist, Clinician Scientist & $\begin{array}{l}\text { Screening and } \\
\text { Diagnosis }\end{array}$ \\
\hline Nanna B. Finnerup MD, DMSc & Aarhus University & Associate Professor & $\begin{array}{l}\text { Screening and } \\
\text { Diagnosis }\end{array}$ \\
\hline Stacey D. Guy, MSocSc, PhD Candidate & Lawson Health Research Institute, Western University & Research Associate & Steering Committee \\
\hline Dan Harvey MA & Spinal Cord Injury Ontario & Peer Support Coordinator & Model of Care \\
\hline Sander L. Hitzig PhD & Toronto Rehabilitation Institute & Affiliate Scientist & $\begin{array}{l}\text { Screening and } \\
\text { Diagnosis }\end{array}$ \\
\hline $\begin{array}{l}\text { Anna Kras-Dupuis RN, MScN, CNNC, } \\
\text { CRN }\end{array}$ & Parkwood Institute & Clinical Nurse Specialist & Treatment \\
\hline $\begin{array}{l}\text { Brenda Lau MD, FRCP(C), } \\
\text { FFPMANZCA, MM, CGIMS }\end{array}$ & The University of British Columbia & $\begin{array}{l}\text { Anesthesiologist, Medical Director } \\
\text { CHANGEpain }\end{array}$ & Model of Care \\
\hline Eldon Loh MD, FRCP(C) & $\begin{array}{l}\text { Lawson Health Research Institute, St. Joseph's Health } \\
\text { Care Pain Clinic, Western University }\end{array}$ & Physiatrist, Assistant Professor & Steering Committee \\
\hline Swati Mehta MA, PhD Candidate & Lawson Health Research Institute, Western University & Research Associate & Steering Committee \\
\hline James W. Middleton PhD & The University of Sydney & Associate Professor & Model of Care \\
\hline Dwight E. Moulin MD, FRCP(C) & St. Joseph's Health Care Pain Clinic, Western University & $\begin{array}{l}\text { Professor, Earl Russell Chair, Pain } \\
\text { Research }\end{array}$ & Treatment \\
\hline Colleen O'Connell MD, FRCP(C) & Stan Cassidy Centre for Rehabilitation & Physiatrist, Research Chief & Model of Care \\
\hline Steve Orenczuk PsyD & Parkwood Institute & Psychologist & $\begin{array}{l}\text { Screening and } \\
\text { Diagnosis }\end{array}$ \\
\hline Andrew G. Parrent MD, FRCSC & Western University, London Health Sciences Center & Associate Professor, Neurosurgeon & Treatment \\
\hline Patrick Potter MD, FRCP(C) & Western University, Parkwood Institute & Physiatrist & Treatment \\
\hline $\begin{array}{l}\text { Philip J. Siddall MBBS PhD } \\
\text { FFPMANZCA }\end{array}$ & The University of Sydney & Professor, Physiatrist & $\begin{array}{l}\text { Screening and } \\
\text { Diagnosis }\end{array}$ \\
\hline Christine Short MD, FRCP(C), FACP & Dalhousie University & $\begin{array}{l}\text { Division head/ chief, Associate Professor, } \\
\text { Physiatrist }\end{array}$ & Treatment \\
\hline Robert Teasell MD, FRCP(C) & Lawson Health Research Institute, Western University & Physiatrist, Scientist & Treatment \\
\hline $\begin{array}{l}\text { Andrea Townson MD, FRCPC, } \\
\text { MScHPEd }\end{array}$ & University of British Columbia & $\begin{array}{l}\text { Clinical Associate Professor, Division Head, } \\
\text { Physiatrist }\end{array}$ & Model of Care \\
\hline Catherine Truchon PhD & Institut national d'excellence en santé et services sociaux & Rehabilitation Trauma Senior Advisor & Model of Care \\
\hline Eva Widerström-Noga DDS, PhD & University of Miami & Research Professor & $\begin{array}{l}\text { Screening and } \\
\text { Diagnosis }\end{array}$ \\
\hline Dalton Wolfe PhD & $\begin{array}{l}\text { Lawson Health Research Institute, Parkwood Institute } \\
\text { Research }\end{array}$ & Scientist & Model of Care \\
\hline
\end{tabular}

including clinical experience, side-effect profile, effectiveness in other $\mathrm{NP}$ populations and any other factors that the panel considered relevant.

Recommendations would subsequently be presented to the full WG, and all members would discuss and vote anonymously on each recommendation using FluidSurvey (an online survey software).

\section{Screening and diagnosis Working Group}

The first meeting of the Screening and Diagnosis Working Group (SDWG) included a review of the questions of interest previously decided upon, an explanation of the process of producing evidence summaries for potentially useful outcome measures, as insufficient evidence was available for assessment using GRADE (as insufficient evidence was available for assessment using GRADE), and a detailed review of the evidence summaries. The SDWG feedback and suggestions about outcome measures provided the basis for developing draft recommendations based on expert opinion. The SC circulated the
Table 2 External reviewers of the CanPainSCI clinical practice guideline

\begin{tabular}{ll}
\hline Name & Affiliation \\
\hline $\begin{array}{l}\text { Lindsey Guilbault } \\
\text { MScPT }\end{array}$ & $\begin{array}{l}\text { St. Joseph's Health Care London, Parkwood Institute } \\
\text { (Physiotherapist) } \\
\text { Keith C. Hayes PhD }\end{array}$ \\
& Western University, Department of Physical \\
& Medicine and Rehabilitation (Professor Emeritus, \\
& Former Department Chair); Ontario Neurotrauma \\
& Foundation (Provincial Lead for SCl Research, \\
& SCl Committee Chair) \\
Keith Sequeira MD, & Western University, Department of Physical \\
FRCP(C) & Pedicine and Rehabilitation; Parkwood Institute, \\
& Director, Spinal Cord Injury and Acquired Brain \\
& Injury Programs) \\
\end{tabular}


Table 3 Recommendations from the CanPainSCI Working Group

\begin{tabular}{|c|c|c|}
\hline \# & Screening and diagnosis recommendations & Type of evidence \\
\hline 1.1 & All patients with spinal cord injury must be screened for pain using a simple yes/no question. & Expert opinion \\
\hline 1.2 & Any member of the health-care team can, and should, screen for the presence of pain. & Expert opinion \\
\hline 1.3 & Screening for pain should occur on admission to rehabilitation, regularly during inpatient rehabilitation and after discharge at each follow-up. & Expert opinion \\
\hline 1.4 & If pain is present at screening, an assessment to determine the type of pain, its intensity and interference should be carried out. & Expert opinion \\
\hline 1.5 & $\begin{array}{l}\text { Diagnosis of neuropathic pain, including its causes, should be informed by (1) a complete patient history, (2) a physical examination, ( } 3 \text { ) the } \\
\text { International Spinal Cord Injury Pain (ISCIP) Classification system and (4) investigations. }\end{array}$ & Expert opinion \\
\hline 1.6 & $\begin{array}{l}\text { Assess for serious underlying conditions (red flags) that may cause, aggravate or mimic neuropathic pain and that require further investigation } \\
\text { and prompt medical review. }\end{array}$ & Expert opinion \\
\hline 1.7 & Assess and manage psychosocial factors (yellow flags) that may contribute to pain-related distress and disability. & Expert opinion \\
\hline 1.8 & $\begin{array}{l}\text { The International Spinal Cord Injury Pain Basic Data Set (ISCIPBDS) v2.0 should be used as a standardized tool for assessing and documenting } \\
\text { pain in patients with spinal cord injury. }\end{array}$ & Expert opinion \\
\hline 1.9 & Address patient concerns, expectations and needs as part of the neuropathic pain assessment. & Expert opinion \\
\hline 1.10 & Standardized evaluation of treatment response should be carried out by the health-care team at regular intervals. & Expert opinion \\
\hline 1.11 & $\begin{array}{l}\text { The evaluation of treatment response should include assessment of changes in pain intensity, mood and function using the International Spinal } \\
\text { Cord Injury Pain Basic Data Set v2.0. Evaluation also includes assessment of adverse events, aberrant behavior and compliance. }\end{array}$ & Expert opinion \\
\hline 1.12 & All patients with new-onset or worsening pain need to be reassessed. & Expert opinion \\
\hline
\end{tabular}

2.1 Pregabalin should be used for the reduction of neuropathic pain intensity among people with spinal cord High Strong injury.

2.2 Gabapentin should be used for the reduction of neuropathic pain intensity among people with spinal cord High Strong injury.

2.3 Amitriptyline can be used for the reduction of neuropathic pain intensity among people with spinal cord High Strong injury.

Second-line therapy

2.4 Tramadol can be used for the reduction of neuropathic pain intensity among people with spinal Strong cord injury.

2.5 Lamotrigine may be considered in those with incomplete spinal cord injury for the reduction of neuropathic Moderate Strong pain intensity.

Third-line therapy

2.6 Transcranial direct current stimulation may be considered for reducing neuropathic pain intensity among High Weak people with spinal cord injury.

2.7 Combined visual illusion and transcranial direct current stimulation may be considered for reducing High Weak neuropathic pain intensity among people with spinal cord injury.

Fourth-line therapy

2.8 Transcutaneous electrical nerve stimulation may be considered for the reduction of neuropathic pain intensity Low Weak among people with spinal cord injury.

2.9 Oxycodone can be used for the reduction of neuropathic pain intensity among people with spinal cord injury. Moderate Weak

2.10 The dorsal root entry zone procedure may be considered in exceptional circumstances and as a last resort for Low Weak reducing neuropathic pain intensity among people with spinal cord injury.

Advise against use

2.11 Levetiracetam should not be used for reducing neuropathic pain intensity among people with spinal cord High Strong injury.

2.12 Mexiletine should not be used for reducing neuropathic pain intensity among people with spinal cord injury. High Strong

\# Model of care recommendations

Type of evidence

3.1 Delivery of care for neuropathic pain in people with spinal cord injury should be (1) coordinated, (2) interprofessional, (3) timely, (4) patientcentered, (5) using a biopsychosocial framework and (6) evidence based.

3.2 A person with spinal cord injury and either (1) new-onset or worsening spinal cord injury-related neuropathic pain, and/or (2) ongoing pain that is difficult to manage, and/or (3) dissatisfaction with their current pain management protocol, should be screened and assessed by a clinician with experience in managing people with spinal cord injury.

3.3 Multidisciplinary care coordinated through a spinal cord injury rehabilitation team is recommended when significant functional impacts and/or significant psychological comorbidity factors resulting from neuropathic pain need to be addressed. Further, a detailed plan of care shared among health-care providers needs to be implemented across primary, secondary and tertiary services.

Expert opinion

Expert opinion

Expert opinion 
Table 3 (Continued)

3.4 A person with neuropathic pain as a result of spinal cord injury should be discharged from specialized care when three conditions are met: (1) a Expert opinion stable plateau has been reached in pain severity and/or pain-related functional status, (2) an ongoing plan linked to resources and provider follow-up is in place and (3) self-management techniques have been taught.

3.5 The spinal cord injury rehabilitation team should engage in continuous quality improvement, including evaluation and feedback efforts regarding Expert opinion their pain management practices based on patient outcomes.

draft recommendations to the SDWG and solicited comments. A review of the recommendations at the second meeting identified a need for more detailed and practical recommendations. Revision of the recommendations included the addition of clinical considerations to elaborate on the recommendations. The clinical considerations included possible differential diagnoses, essential and contextual elements of the history and physical examination, and work-up for a patient with new-onset or worsening below- or at-level NP. The clinical considerations were based primarily on clinical experience and comprise the main elements of a clinical assessment. The next meeting of the SDWG reviewed the recommendations and discussed next steps. After this meeting, the SDWG voted on the draft recommendations, including the clinical considerations, and achieved consensus.

\section{Treatment Working Group}

The first meeting of the Treatment Working Group (TWG) included a review of the questions of interest and an explanation of the process of producing the evidence tables. The TWG also began reviewing the evidence tables, which included one for each potential pain treatment therapy or modality. On the basis of TWG feedback, the SC revised these tables to include the outcome effects. Pharmacologic therapy was reviewed during the first two meetings and nonpharmacologic therapy was reviewed at the third meeting, which also reviewed draft recommendations for pharmacologic therapy. The fourth meeting discussed decisions about the pharmacologic therapy recommendations and reviewed nonpharmacologic therapy recommendations. The TWG decided that treatments for which insufficient evidence existed to make a recommendation would be treated as research recommendations. The SC then revised the treatment and research recommendations. The TWG then voted on the treatment recommendations and line of therapy for each treatment. This process is described in greater detail in the paper describing treatment recommendations (this issue). The next meeting of the subgroup reviewed the results of the voting and made final adjustments to the recommendations before the full WG meeting.

\section{Model of Care Working Group}

The literature search identified no evidence for SCI-specific models of care for pain management, although evidence was identified for models of care for pain management in general. As a result of the lack of evidence, recommendations produced by the Model of Care Working Group (MCWG) would be based on expert opinion. The first meeting of the MCWG discussed existing models of care, suggestions for developing a model of care and cost-effectiveness. The SC drafted recommendations for discussion at the next meeting. The next two meetings of the MCWG reviewed these draft recommendations, suggested modifications and discussed next steps. The SC revised the recommendations, and the MCWG members voted on them and achieved consensus.

\section{CanPainSCI WG meetings}

Two face-to-face meetings were held. The first meeting, held in Toronto, Canada (November 2014), was facilitated by the SC and a consultant. The purpose of this 2-day meeting was to discuss and reach consensus on the recommendations proposed by each subgroup. The day was divided into reviewing and adding clarity to the recommendations, according to topic. Once the WG was comfortable with the recommendations, the consensus process moved to an online, real-time, anonymous vote at and after the meeting. Only recommendations achieving $>75 \%$ agreement were finalized. Recommendations achieving $<75 \%$ agreement were revised until consensus was reached. This discussion elicited clinical considerations that the WG felt necessary to include in the guidelines to provide context and further detail about implementing the recommendations. Different ways of displaying the guidelines were explored, and considerations for updating the CPGs and developing knowledge products were shared.

The second meeting, which a majority of panelists attended, took place in Montreal, Canada (May 2015), and determined specific factors affecting allocation of therapies to a line of treatment, including current clinical practice, motivations for policy changes and drug treatment, and clinical considerations. No voting was done at this meeting.

\section{External review}

The complete drafted supplement was sent for external review in January 2016. Using the AGREE II tool, the quality of these guidelines was assessed by three external reviewers (Table 2). The manuscripts were revised based on suggestions from these reviewers. In each domain, the score ranged from 6 to 7 across all reviewers.

\section{Recommendations}

The CanPainSCI WG developed 30 recommendations for NP divided into recommendations for this issue: screening and diagnosis, treatment and model of care. The specific papers contain the recommendations and clinical considerations that apply to each recommendation (Table 3).

\section{Applicability}

Future work for the SC includes the development of practical implementation strategies. Throughout the CPG development process, the SC has tracked potential barriers and facilitators of implementation. These will be explored in the next phase of this work, including audience-specific implementation tools. Preliminary thoughts regarding sustainable implementation include obtaining support of leadership and/or administration, training health-care providers through workshops to raise awareness, identifying practice champions among site-specific health-care providers and following a theory-driven implementation strategy. We recognize that the cost of management strategies and the allocation of resources are a significant challenge to implementation. We hope that this CPG is a stepping stone to revising 
the distribution of resources. In addition, we have considered applicability throughout the supporting papers.

\section{Updating}

The process of updating these CPG will begin in 2018 (pending available funding). This will include convening a WG of experts and consumers to review any new evidence within the field and consequently decide whether the new evidence changes the recommendations.

\section{CONCLUSION}

These guidelines represent the first Canadian CPG for the management of at- and below-level NP after SCI and the first to be developed in accordance with the AGREE II tool. In addition to informing clinical practice, these guidelines should be useful in establishing future research directions.

\section{CONFLICT OF INTEREST}

BL has received consulting fees from the Northern Regional Health Authority (2014-2016), founded the CHANGEpain Clinic, has received fees for lecturing from DePuy and has served as expert witness. CO'C has received consulting fees from Bonify (2015-current), Lilly (2014) and Allergan (2013-current), has received lecture fees from Allergan, Biogen, Purdue, Lilly, Tweed, Tilray, Quality Respiratory Care and Respironics, has received grant support from Cytokinetics (2013-current), Biogen (2010-current), Acorda (2005-2010; 2015-current), Allergan (2010-current) and Sensimat 2015 and has served as expert witness on disability, at the request of third parties including CMPA, insurance companies and law firms. TNB has received grant support from the Craig Neilsen Foundation (2015) and Allergan (2015). BCC has received consulting fees from Allergan (2013) and the Rick Hansen Institute (2013) and has received grant support from the Rick Hansen Institute (2014-2016), the Ontario Neurotrauma Foundation (2011-2018), the Canadian Institutes for Health Research (2008-2016) and the Rick Hansen Institute \& SCI Solutions Network (2012-2015). NBF has received grant support from IMI Europain (EU/EFPIA, 2009-2015). DEM has received consulting fees from Johnson and Johnson (2014), fees for lecturing from Lilly (2014), Merck-Frosst (2014) and Purdue Pharma (2013), has received grant support from Pfizer (2009-2014) and has received book royalties from Cambridge University Press. PJS has received grants from the Australian \& New Zealand College of Anesthetists (2015) and the New South Wales state government (2013-2015) and holds a patent for a system and method for detecting pain and its components using magnetic resonance spectroscopy, US Patent 08755862, granted 17 June 2014. RT has received grant support (2013-2016) and lecture fees (2015) from Allergan. The remaining authors declare no conflict of interest.

\section{ACKNOWLEDGEMENTS}

Funding for the research and publication of this supplement is provided by the Ontario Neurotrauma Foundation and the Rick Hansen Institute in their mission to advance the care of people with spinal cord injury (\#PM2 964). We thank Joanna Gorski for her help with manuscript preparation.
1 Davidoff G, Roth E, Guarracini M, Silwa J, Yarkony G. Function-limiting dysesthetic pain syndrome among traumatic spinal cord injury patients: a cross-sectional study. Pain 1987; 29: 39-48.

2 Cohen M, McArthur D, Vulpe M, Schandler S, Gerber K. Comparing chronic pain from spinal cord injury to chronic pain of other origins. Pain 1988; 35: 57-63.

3 Rose M, Robinson J, Ells P, Cole J. Pain following spinal cord injury: results from a postal survey. Pain 1988; 34: 101-102.

4 Britell C, Mariano A. Chronic pain in spinal cord injury. Phys Med Rehabil 1991; 5: 71-82.

5 Mariano A. Chronic pain and spinal cord injury. Clin J Pain. 1992; 8: 87-92.

6 Cairns D, Adkins R, Scott M. Pain and depression in acute traumatic spinal cord injury: origins of chronic problematic pain? Arch Phys Med Rehabil 1996; 77: 329-335.

7 Modirian E, Pirouzi P, Soroush M, Karbalaie-Esmaeili S, Shojaei H, Zamani H. Chronic pain after spinal cord injury: results of a long-term study. Pain Med 2010; 11: 1037-1043.

8 Siddall PJ. Management of neuropathic pain following spinal cord injury: now and in the future. Spinal Cord. 2009; 47: 352-359.

9 Kewman DG, Tate DG. Suicide in SCI: a psychological autopsy. Rehabil Psychol 1998; 43: 143-151.

10 Murphy D, Reid DB. Pain treatment satisfaction in spinal cord injury. Spinal Cord 2001; 39: 44-46.

11 Heutink M, Post M, Wollaars M, Asbeck F. Chronic spinal cord injury pain: pharmacological and non-pharmacological treatments and treatment effectiveness. Disabil Rehabil 2011; 33: 433-440.

12 Chronic Pain \& Spinal Cord Injury Project Report 2: Clinician Needs Analysis. Chatswood, NSW: NSW ACI Pain Network \& NSW State Spinal Cord Injury Service; 2013.

13 Craven C, Verrier M, Balioussis C, Wolfe D, Hsieh J, Noonan V et al. Rehabilitation Environmental Scan Atlas: Capturing Capacity in Canadian SCl Rehabilitation. Rick Hansen Institute: Toronto, ON. 2012.

14 Siddall P, Middleton J. A proposed algorithm for the management of pain following spinal cord injury. Spinal Cord 2006; 44: 67-77.

15 Spinal Cord Injury Research Evidence (SCIRE) Project. Available at http://www.scireproject.com/rehabilitation-evidence (accessed on 2 December 2015).

16 Brouwers M, Kho ME, Browman GP, Cluzeau F, Feder G, Fervers B et al. AGREE II: advancing guideline development, reporting and evaluation in healthcare. Can Med Assoc J 2010; 182: E839-E842.

17 MASCIP Multidisciplinary Association of Spinal Cord Injury Professionals. Guidelines for the Management of Neuropathic Pain in Adults following Spinal Cord Injury. 2nd ed, 2008. Available at http://www.mascip.co.uk/guidelines.aspx (accessed on 20 August 2014).

18 Perrouin-Verbe B, Ventura M, Albert T, Souan P, Fattal C, Revel M. Clinical practice guidelines for chronic neuropathic pain in the spinal cord injury patient: introduction and methodology. Ann Phys Rehabil Med 2009; 52: 77-82.

19 Guyatt G, Oxman AD, Akl EA, Kunz R, Vist G, Brozek J et al. GRADE guidelines: 1. Introduction-GRADE evidence profiles and summary of findings tables. J Clin Epidemiol. 2011; 64: 383-394.

cc) (i) () $\odot$ This work is licensed under a Creative Commons Attribution-NonCommercial-NoDerivs 4.0 International License. The images or other third party material in this article are included in the article's Creative Commons license, unless indicated otherwise in the credit line; if the material is not included under the Creative Commons license, users will need to obtain permission from the license holder to reproduce the material. To view a copy of this license, visit http://creativecommons.org/licenses/bync-nd/4.0/

(C) The Author(s) 2016

Supplementary Information accompanies this paper on the Spinal Cord website (http://www.nature.com/sc) 